\title{
Palladium-Catalyzed Benzene Arylation: Incorporation of Catalytic Pivalic Acid as a Proton Shuttle and a Key Element in Catalytic Design
}

\author{
Marc Lafrance and Keith Fagnou*
}

Center for Catalysis Research and Innovation, University of Ottawa, Department of Chemistry, 10 Marie Curie, Ottawa, Ontario, Canada K1N 6N5

Keith.Fagnou@uottawa.ca

\section{Supporting Information}

\section{General Methods:}

All experiments were carried out under an atmosphere of argon. ${ }^{1} \mathrm{H}$ and ${ }^{13} \mathrm{C}$ NMR were recorded in $\mathrm{CDCl}_{3}$ solutions using a Bruker AVANCE 400 spectrometer. High-resolution mass spectra were obtained on a Kratos Concept IIH. Infra-Red analysis was performed with a Bruker EQUINOX 55. HPLC Grade benzene, pentane, $\mathrm{Et}_{2} \mathrm{O}$ and hexane were employed. Dimethylacetamide and benzene were degassed with Argon prior to every use. Palladium sources were stored in a dessicator and were weighed out to air unless otherwise specified. All other reagents and solvents were used as is from commercial sources. Unless noted below, all other compounds have been reported in the literature or are commercially available.

\section{Table of Contents}

Procedure for Direct Arylation of Benzene $\quad$ S1

Kinetic Isotope Effect Experiments $\quad$ \$4

Competitions Studies $\quad$ S5

$\begin{array}{ll}\text { DFT Calculations } & \text { S7 }\end{array}$

\section{Procedure for the Direct Arylation of Benzene}

\section{General Procedure:}

$\mathrm{K}_{2} \mathrm{CO}_{3}$ (2.5 equiv.) was weighed to air and placed in a Schlenk tube $(15 \mathrm{ml})$ or screw capped vial $(2 \mathrm{~mL})$ with a magnetic stir bar. The reaction vessel was evacuated and backfilled with argon (x3). The aryl halide (1 equiv.) was then added to the Schlenk tube as a solution in benzene $(0.21 \mathrm{M})$. $\mathrm{Pd}(\mathrm{OAc})_{2}(3 \mathrm{~mol} \%)$, DavePhos ( $3 \mathrm{~mol} \%)$ and pivalic acid (0.3 eq.) were then added as a solution in 
DMA (1.16 times the volume of benzene) and the reaction was heated to $120^{\circ} \mathrm{C}$ for 12 hours. Upon completion, the reaction was cooled to room temperature. If possible the solvents were removed by distillation and the resulting mixture was purified by a silica gel packed flash chromatography column typically using hexane or pentane/ether mixtures as the eluent. If the product is too volatile for removal of the DMA by distillation, it was loaded directly onto a silica gel packed flash chromatography column.

\section{4-phenyltoluene ${ }^{1}$}<smiles>Cc1ccc(-c2ccccc2)cc1</smiles>

The compound was prepared following the general procedure using $110 \mathrm{mg}$ of 4bromotoluene in $81 \%$ yield. The reaction was loaded onto a silica pad and was eluted using hexane in order to remove the DMA which does not elute. The resulting mixture was then purified by preparative TLC using pentane as the eluent.

\section{3-phenyltoluene ${ }^{1}$}<smiles>Cc1cccc(-c2ccccc2)c1</smiles>

The compound was prepared following the general procedure using $110 \mathrm{mg}$ of 3bromotoluene in $83 \%$ yield. The reaction was loaded onto a silica pad and was eluted using hexane in order to remove the DMA which does not elute. The resulting mixture was then purified by preparative TLC using pentane as the eluent.

\section{2-phenyltoluene ${ }^{1}$}<smiles>Cc1ccccc1-c1ccccc1</smiles>

The compound was prepared following the general procedure using $110 \mathrm{mg}$ of 2bromotoluene in $85 \%$ yield. The reaction was loaded onto a silica pad and was eluted using hexane in order to remove the DMA which does not elute. The resulting mixture was then purified by preparative TLC using pentane as the eluent. 


\section{3-methyl-4-phenylnitrobenzene ${ }^{2}$}<smiles>Cc1cc([N+](=O)[O-])ccc1-c1ccccc1</smiles>

The compound was prepared following the general procedure using $139 \mathrm{mg}$ of 2bromo5-nitrotoluene in $81 \%$ yield. The reaction was performed on $139 \mathrm{mg}$ and was purified by removal of DMA by distillation followed by a silica chromatography column using a $2 \%$ ether/hexane eluent.

\section{3-phenylanisole ${ }^{3}$}<smiles>COc1cccc(-c2ccccc2)c1</smiles>

The compound was prepared following the general procedure using $119 \mathrm{mg}$ of 3bromoanisole in $69 \%$ yield. The product was purified by removal of DMA by distillation followed by a silica chromatography column using $2 \%$ ether/hexane eluent.<smiles>c1ccc(-c2cccc3ccccc23)cc1</smiles>

The compound was prepared following the general procedure using 133mg of 1bromonaphtalene in $80 \%$ yield. The reaction was loaded onto a silica pad and was eluted using hexane in order to remove the DMA which does not elute. The resulting mixture was then purified by preparative TLC using pentane as the eluent.

\section{2-phenylnaphthalene ${ }^{1}$}<smiles>c1ccc(-c2ccc3ccccc3c2)cc1</smiles>

The compound was prepared following the general procedure using $133 \mathrm{mg}$ of 2bromonaphtalene in 55\% yield. The resulting mixture was then purified by preparative TLC using pentane as the eluent. 


\section{3-phenylchlorobenzene ${ }^{4}$}<smiles>Clc1cccc(-c2ccccc2)c1</smiles>

The compound was prepared following the general procedure using 123mg of 3bromochlorobenzene in $63 \%$ yield. The reaction was loaded onto a silica pad and was eluted using hexane in order to remove the DMA which does not elute. The resulting mixture was then purified by preparative TLC using pentane as the eluent.

\section{Kinetic Isotope Effect Experiments}<smiles>[2H]c1c([2H])c([2H])c([2H])c([2H])c1[2H]</smiles><smiles></smiles>

53 equiv.

53 equiv.

$k_{H} / k_{D}=5.5$

$\mathrm{K}_{2} \mathrm{CO}_{3}(0.225 \mathrm{~g}, 2.5$ equiv.) was weighed to air and placed in a Schlenk tube $(15 \mathrm{ml})$ with a magnetic stir bar. The reaction vessel was evacuated and backfilled with argon (x3). 4-bromoanisole (0.122g, 1 equiv.) was then added to the Schlenk tube as a solution in Benzene- $\mathrm{H}_{6}(3 \mathrm{~mL})$ and Benzene- $\mathrm{D}_{6}(3 \mathrm{~mL})$. $\mathrm{Pd}(\mathrm{OAc})_{2}(0.004 \mathrm{~g}, 0.03$ equiv.), DavePhos (0.008g, 0.03 equiv.) and pivalic acid $(0.02 \mathrm{~g}, 0.3$ equiv.) were then added as a stock solution in DMA $(7 \mathrm{~mL})$ and the reaction was heated to $120^{\circ} \mathrm{C}$ for 12 hours. Upon completion, the reaction was cooled to room temperature. The resulting mixture was then loaded directly onto a silica gel packed flash chromatography column and eluted with $1 \%$ ether/hexane mixture. The product distribution was then analyzed by ${ }^{1} \mathrm{HNMR}$ and MS.

NOTE: 4-Bromoanisole was used in this experiment because the shift of the anisole protons in the ${ }^{1} \mathrm{H}$ NMR facilitated a quantitative analysis of the product distribution by avoiding peak overlap which was the case with 4-bromotoluene. 


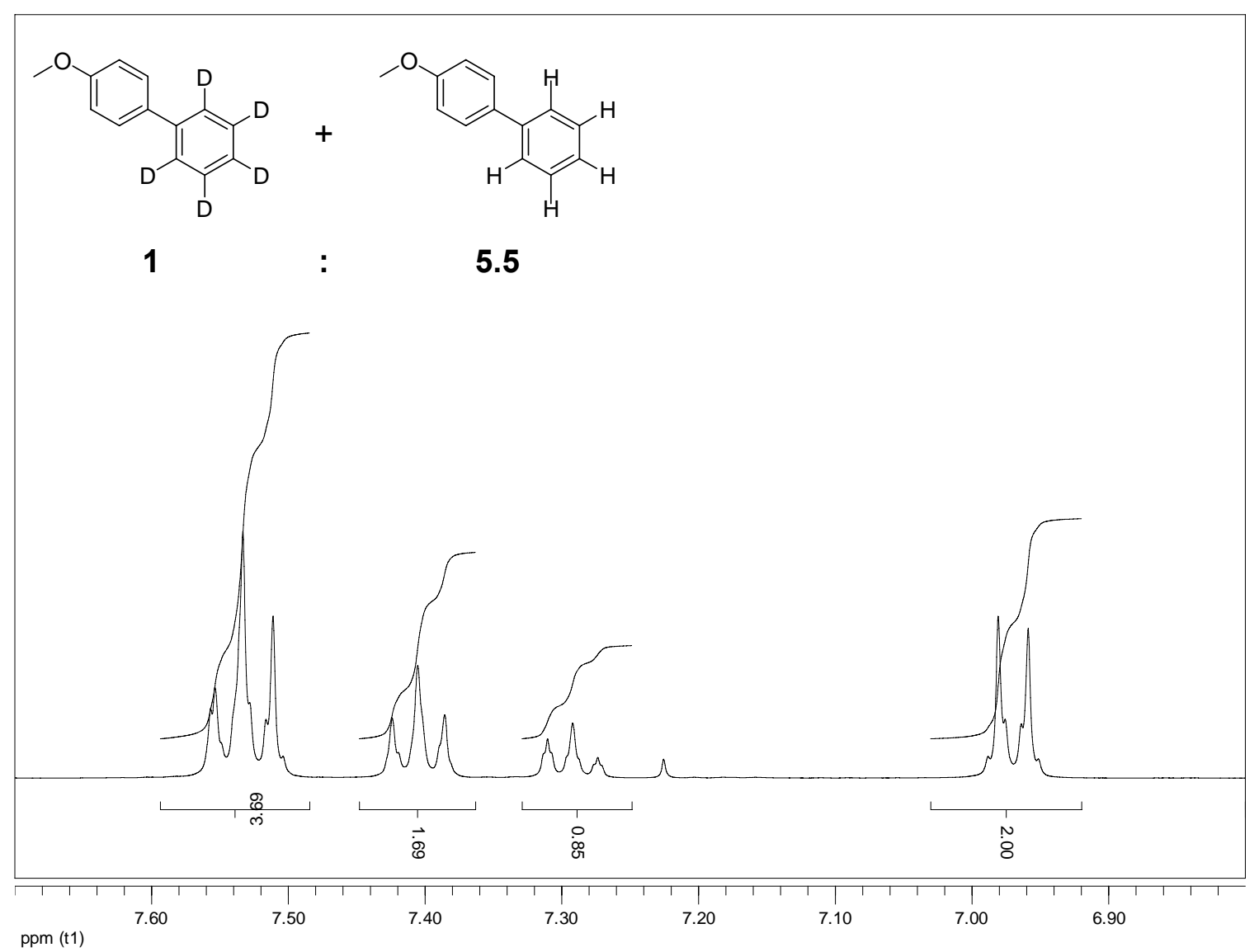

\section{Competitions Studies}<smiles>c1ccccc1</smiles>

53 equiv.<smiles>Fc1ccccc1</smiles>

53 equiv.
$3 \mathrm{~mol} \% \mathrm{Pd}(\mathrm{OAc})_{2}$, $3 \mathrm{~mol} \%$ DavePhos, 0.3 eq. $\mathrm{PivOH}$ $\underset{\mathrm{K}_{2} \mathrm{CO}_{3}, \mathrm{DMA}}{120^{\circ} \mathrm{C}}$
$\stackrel{\longrightarrow}{12}$<smiles>Cc1ccc(-c2ccc(F)cc2)cc1</smiles>

$$
0: m: p=22: 3: 1
$$

B

$A / B=\sim 11: 1$

$\mathrm{K}_{2} \mathrm{CO}_{3}(0.225 \mathrm{~g}, 2.5$ equiv.) was weighed to air and placed in a Schlenk tube $(15 \mathrm{ml})$ with a magnetic stir bar. The reaction vessel was evacuated and backfilled with argon (x3). 4-bromotoluene $(0.110 \mathrm{~g}, 1$ equiv.) was then added to the Schlenk tube as a solution in benzene $(3 \mathrm{~mL})$ and fluorobenzene $(3 \mathrm{~mL})$. 
$\mathrm{Pd}(\mathrm{OAc})_{2}(0.004 \mathrm{~g}, 0.03$ equiv.), DavePhos (0.008g, 0.03 equiv.) and pivalic acid $(0.02 \mathrm{~g}, 0.3$ equiv.) were then added as a stock solution in DMA $(7 \mathrm{~mL})$ and the reaction was heated to $120^{\circ} \mathrm{C}$ for 12 hours. Upon completion, the reaction was cooled to room temperature. The resulting mixture was analyzed by GCMS and then filtered through a small silica pad $(5 \mathrm{~cm})$ using hexane as the eluent. The product distribution was then assigned by GCMS. The regioisomeric distribution was establish by ${ }^{19} \mathrm{~F}$ NMR and compared with literature values ${ }^{5}$.

The regioisomeric products of reaction with fluorobenzene were also prepared and isolated in $91 \%$ yield as described below.

\section{fluoro-4-methylbiphenyl}<smiles>Cc1ccc(-c2ccccc2)cc1</smiles>

The compound was prepared following the general procedure using $110 \mathrm{mg}$ of 4bromotoluene as well as using fluorobenzene instead of benzene in $91 \%$ yield as a o:m:p regiomeric distribution of $22: 3: 1$ as determined by ${ }^{19} \mathrm{~F} \mathrm{NMR}$. The reaction was loaded onto a silica pad and was eluted using hexane in order to remove the DMA which does not elute. The resulting mixture was then purified by a silica chromatography column using $100 \%$ hexane eluent.

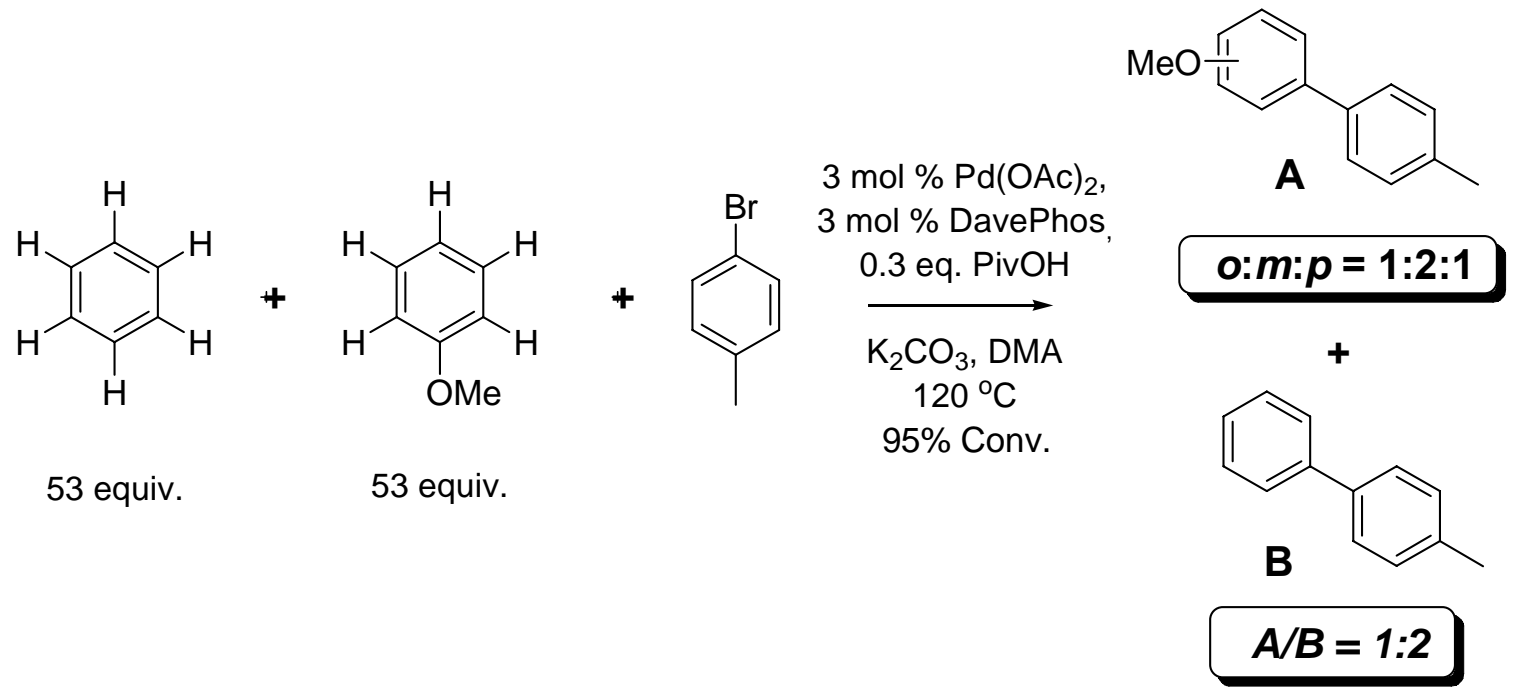

$\mathrm{K}_{2} \mathrm{CO}_{3}(0.225 \mathrm{~g}, 2.5$ equiv.) was weighed to air and placed in a Schlenk tube $(15 \mathrm{ml})$ with a magnetic stir bar. The reaction vessel was evacuated and backfilled with argon ( $x 3)$. 4-Bromotoluene $(0.110 \mathrm{~g}, 1$ equiv.) was then added to the Schlenk tube as a solution in benzene $(3 \mathrm{~mL})$ and anisole $(3 \mathrm{~mL}) . \mathrm{Pd}(\mathrm{OAc})_{2}$ (0.004g, 0.03 equiv.), DavePhos ( $0.008 \mathrm{~g}, 0.03$ equiv.) and pivalic acid $(0.02 \mathrm{~g}, 0.3$ equiv.) were then added as a stock solution in DMA $(7 \mathrm{~mL})$ and the reaction was 
heated to $120^{\circ} \mathrm{C}$ for 12 hours. Upon completion, the reaction was then cooled to room temperature. The resulting mixture was analyzed by GCMS against authentic samples in order to assign the product distribution.

The regioisomeric products of reaction with anisole were also prepared and isolated in 91\% yield as described below.

\section{methoxy-4-methylbiphenyl}<smiles>COc1ccccc1-c1ccc(C)cc1</smiles>

The compound was prepared following the general procedure using $110 \mathrm{mg}$ of 4bromotoluene as well as using anisole instead of benzene in $62 \%$ yield as a o:m:p regiomeric distribution of $1: 2: 1$ by GCMS and comparison to authentic samples. The reaction was loaded onto a silica pad and was eluted using $2 \%$ ether/hexane mixture in order to remove the DMA which does not elute. The resulting mixture was then purified by preparative TLC using $2 \%$ ether/hexane as the eluent.

\section{DFT Calculations}

All calculations were performed with the Jaguar 6.0 software package. ${ }^{1}$ The triple-zeta basis set, LAV3P+**, that includes diffuse functions and a more complete set of polarization functions and ECP combination of Jaguar was used. Energies reported are electronic energies with no thermal or solvent corrections. A smaller model system was used for the catalyst by replacing the dicyclohexylbiarylphosphine ligand with a $\mathrm{PH}_{3}$ ligand. This is a typical approach used in quantum chemical calculations to reduce computation times. The effect of the phosphine ligand is not expected to change the qualitative nature of these calculations. The transition state energies were determined in the same manner as that used in our previous report dealing with perfluorobenzenes which were determined to occur via an identical mechanism as that explored here. ${ }^{2}$

\footnotetext{
${ }^{1}$ Jaguar 6.0; Schrodinger, LLC: Portland, Oregon, 2004

${ }^{2}$ M. Lafrance, C.N. Rowley, T.K. Woo, K. Fagnou, K. J. Am. Chem. Soc. 2006, 128, 8754.
} 
Figure S1. Transition state structure for the hydrogen abstraction from benzene by pivalic acid base.

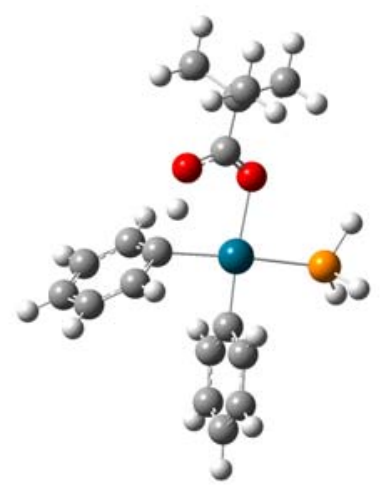

Table S1. Comparison of bases for rate-limiting hydrogen abstraction step. Uncorrected electronic energies in $\mathrm{kcal} / \mathrm{mol}$ (B3LYP/LAV3P+**).

\begin{tabular}{|c|c|c|}
\hline Anion & $\mathbf{\Delta E}^{\ddagger}$ & $\mathbf{\Delta E}$ \\
\hline pivalate & 24.9 & 13.3 \\
\hline bicarbonate & 26.2 & 16.8 \\
\hline
\end{tabular}

\footnotetext{
${ }^{1}$ Zim, D.; Lando, V.R.; Dupont, J.; Monteiro, A.L. Org. Lett. 2001, 3, 3049.

${ }^{2}$ Iihama, T.; Fu J.-M.; Bourguignon, M. ; Snieckus, V. Synthesis, 1989, 3, 184.

${ }^{3}$ Mino, T.; Shirae, Y.; Sakamoto, M.; Fujita, T. J. Org. Chem. 2005, 70, 2191.

${ }^{4}$ Wilson, N. J. Am. Chem. Soc. 1975, 97, 3573.

${ }^{5}$ Kelm, J. and Strauss, K. Spectrochimica Acta, 1981, 37A, 689.
} 